\title{
Shot-peening of carbonitrided steel: influence of the process on the mechanical state
}

\author{
S. Van Wijk ${ }^{1}$, M. François ${ }^{1}$ and E. Sura ${ }^{2}$ \\ ${ }^{1}$ Université de Technologie de Troyes (UTT), ICD LASMIS, UMR CNRS 6279, 12 rue Marie Curie, \\ BP 2060, 10010 Troyes Cedex, France \\ ${ }^{2}$ Direction Ingénierie Process, Renault, 67 rue des bons raisins, 92508 Rueil-Malmaison, France
}

\begin{abstract}
Residual stresses have a significant role in affecting engineering properties of materials and shot peening process is an effective production technique to ensure required residual stress levels. This paper presents an analysis of an orthogonal design of experiment to establish an empirical relationship between main parameters of shot peening process and residual stress profiles for a carbonitrided steel. The hardening / softening evolution of the material is followed using hardness and diffraction peak width. Four critical peening parameters, i.e. shot size, incident angle, exposure time, airblast pressure, have been chosen and the range of peening conditions are established by using the Taguchi technique. In this study, a shot velocity measurement system is used to obtain the on-line velocity during the peening process and the relationship between the maximum compressive residual stresses and the shot velocity is also developed. Analysis of the experimental data showed that it is possible to optimize the shot peening process by an effective control of process parameters.
\end{abstract}

\section{Introduction}

Shot peening is a cold working process which enhance the mechanical properties of a metallic component by blasting a stream of spherical particles against a metal component. The process can be viewed as a multiple and progressively repeated impact in a piece by spheres which are projected against the surface with sufficient velocities to indent the surface [1]. The indentation at each point of impact is the result of local plastic deformation. As the deformed regions tend to expand, they are restrained by deeper metal which was not plastically deformed by shot impacts. Since the plastically deformed surface layer seeks to occupy more space, it is compressively strained elastically. This compressively stressed layer is extremely effective in preventing premature failure under conditions of cyclic loading since fatigue cracks generally initiate at the free surface and is accelerated by tensile stresses. Hardness is related to several parameters such as residual stresses, yield stress and work hardening and it gives interesting information on the capacity of the treated material to carry static and applied loads and, in particular, contact loads [2,3]. Shot peening involves a wide range of process parameters which may have a significant effects on the level of residual stress and hardness. It is thus necessary to choose the relevant factors by analyzing previous works, and then to quantify the effects of shot peening parameters, and in particular to predict the value of the residual stresses and hardness which will result from processing the surface with given conditions. In this paper, a statistical design of experiments (DoE) based on the Taguchi methodology is used as a simple and

This is an Open Access article distributed under the terms of the Creative Commons Attribution-Noncommercial License 3.0, which permits unrestricted use, distribution, and reproduction in any noncommercial medium, provided the original work is properly cited. 
efficient method to determine the responses for a given set of factors. Due to cost and practical considerations, an incomplete factorial design was adopted.

\section{Design of experiment}

\subsection{Setting the level of the selected process parameters}

Based on previous works [4-10] on the factors which have the most influence on distribution of residual stress, four main parameters have been selected in this study: shot diameter, angle of impact, exposure time and pressure. Angle of impact represents the relative angle between the nozzle and the surface of the specimen $\left(90^{\circ}\right.$ is normal to the surface). Exposure time is the effective time of the treatment. Pressure is the air pressure used to deliver the stream of media to the surface to be peened. Two levels have been selected for each parameter as shown in Table 1. During the process of shot peening, the following factors were held constant: shot type of G3, shot hardness of $640 \mathrm{HV}$ and mass flow of $13 \mathrm{~kg} /$ minute.

\begin{tabular}{lll}
\hline Parameters & Lower level -1 & Higher level 1 \\
\hline$\varnothing:$ shot size $(\mathrm{mm})$ & 0.3 & 0.7 \\
$\Theta:$ angle of impact $\left({ }^{\circ}\right)$ & 65 & 85 \\
$t:$ exposure time $(\mathrm{s})$ & 3 & 6 \\
$P:$ pressure $(B a r)$ & 3 & 5 \\
\hline
\end{tabular}

Table 1. Factors levels for the experiment.

\subsection{Designing the experiment}

The Taguchi table L8 with two levels for each parameter was used to establish the DoE because of its simplicity and efficiency compared with the full design. Taguchi method uses a special design called orthogonal arrays to study the entire parameter space with only a small number of experiments [5]. An analysis of variance is performed to identify the process parameters that are statistically significant. The optimal combination of the process parameters can then be predicted based on the above analysis. A full design for two levels of four factors requires 16 configurations whereas the Taguchi table needs 8 configurations. The detailed information for the configurations is shown in Table 2. It must be noted that, because we do not use a full design with 16 configurations, some effects are aliased. It means that all the interactions cannot be extracted from the measured responses. These aliasing are reported in Table 5. If third order interactions are assumed to be negligible, the direct effect of the main factors can be obtained.

\begin{tabular}{lllll}
\hline Configuration & $\varnothing$ & $\Theta$ & $t$ & $P$ \\
\hline 1 & -1 & -1 & -1 & -1 \\
2 & -1 & -1 & 1 & 1 \\
3 & -1 & 1 & -1 & 1 \\
4 & -1 & 1 & 1 & -1 \\
5 & 1 & -1 & -1 & 1 \\
6 & 1 & -1 & 1 & -1 \\
7 & 1 & 1 & -1 & -1 \\
8 & 1 & 1 & 1 & 1 \\
\hline
\end{tabular}

Table 2. Configurations established by the L8 orthogonal array.

\subsection{The experimental conditions}


Specimens of dimensions $80 \times 16 \times 9 \mathrm{~mm} 3$ with steel $27 \mathrm{MnCr} 5$ were manufactured. They were carbonitrided and exhibit a level of hardness of approximately $2146 \mathrm{MPa}$, which is harder than the shot medium. The time to obtain $100 \%$ coverage is estimated as 3 seconds.

The measurement of residual stresses was performed by X-ray diffraction method. The in-depth measurement was obtained by successive electrochemical layer removal. Hardness was measured by a Micro Vickers hardness machine. Table 3 shows the experiment conditions.

\begin{tabular}{lc}
\hline & X ray diffraction \\
Diffractometer & Seifert XRD 3000 Pts, 4 circles \\
Residual stress measurement & $\operatorname{Sin}^{2} \Psi$ method, peak fitting with a \\
& pseudo-Voigt function and K doublet \\
Lattice plan & $\{211\}$ \\
Detector type & Position sensitive detector \\
Radiation & Cr K (V filter) \\
$\Psi$ Number & From $-45^{\circ}$ to $45^{\circ}$ with $11 \Psi$ \\
Measure uncertainty & $\pm 5 \mathrm{MPa}$ (standard deviation) \\
& Hardness \\
Hardness machine & Mitutoyo AVK $-\mathrm{C} 1$ \\
Charge & $98 \mathrm{~N}$ \\
Measure uncertainty & $\pm 71 \mathrm{MPa}$ (standard deviation) \\
\hline
\end{tabular}

Table 3. Experiment conditions.

\section{Results and discussion}

\subsection{Residual stresses}

For each configuration, stresses profiles along the depth were measured. The absolute values of surface stress and maximum stress are shown by Table 4 . An example of stress profile is presented in Figure 1 to indicate the stress level in configuration 6. The effect of each main factor and of all the second order interactions on surface stress and maximum stress are shown in Table 5.

\begin{tabular}{cccc}
\hline Configuration & $\begin{array}{l}\text { Surface } \\
\text { stress }(M P a)\end{array}$ & $\begin{array}{l}\text { Maximum } \\
\text { stress }(M P a)\end{array}$ & $\begin{array}{l}\text { Depth of } \\
\text { maximum } \\
\text { stress }(\mu m)\end{array}$ \\
\hline 1 & 465 & 883 & 18 \\
2 & 388 & 1119 & 18 \\
3 & 453 & 1224 & 54 \\
4 & 502 & 1166 & 18 \\
5 & 333 & 1040 & 54 \\
6 & 422 & 1136 & 36 \\
7 & 470 & 840 & 54 \\
8 & 364 & 1177 & 30 \\
\hline \multicolumn{4}{c}{ Average stress } \\
\hline \multicolumn{4}{c}{1073} \\
\hline
\end{tabular}

Table 4. Stress values measured by XRD.

It can be observed on Figure 1 that the residual stress profile does not go towards positive values when the depth increases: it remains constant at about $-400 \mathrm{MPa}$ after $200 \mu \mathrm{m}$. This is due to the initial profile coming from carbonitriding which gives compressive stresses up to about $630 \mu \mathrm{m}$. This was observed on all the specimens. 


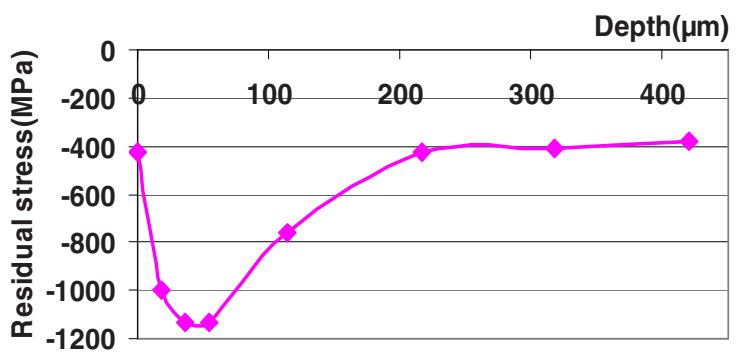

Fig. 1. Stress profile to configuration 6 .

\subsubsection{Effect of velocity of projection on stress level}

In the DoE, pressure, because it is a convenient process factor, was considered. However, it is not very easy to interpret with regard to the physical phenomena occurring in the treated component. Shot velocity, on the other hand, is directly connected to the kinetic energy of shot and thus to the energy transmitted to the material. For this reason, velocity measurements were performed for three pressure values and two shot sizes. Results are reported on Figure. 2. It can be observed that the evolution of velocity with pressure is quasi linear and the velocity is higher for smaller shot size.

The measured residual stresses are reported versus the component of shot velocity normal to the treated surface. It can be seen in Figure 3 that the maximum stress increases with velocity while surface stress remains almost constant. Meguid et al [6] and Hong et al [7] have studied the shot peening process with the numerical simulation and show that increase in the shot velocity results in a significant increase in the maximum stress. Hong et al [7] has shown that the shot velocity appeared to have little effect on the magnitude of the surface residual stress. These results from literature are consistent with our study.

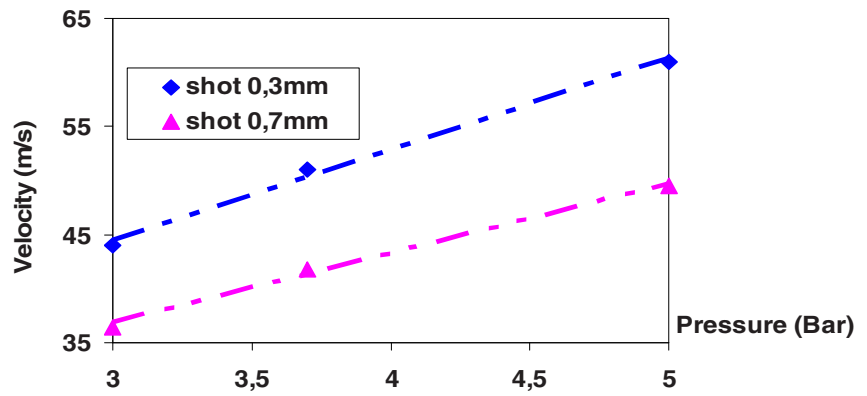

Fig. 2. Shot velocity vs pressure.

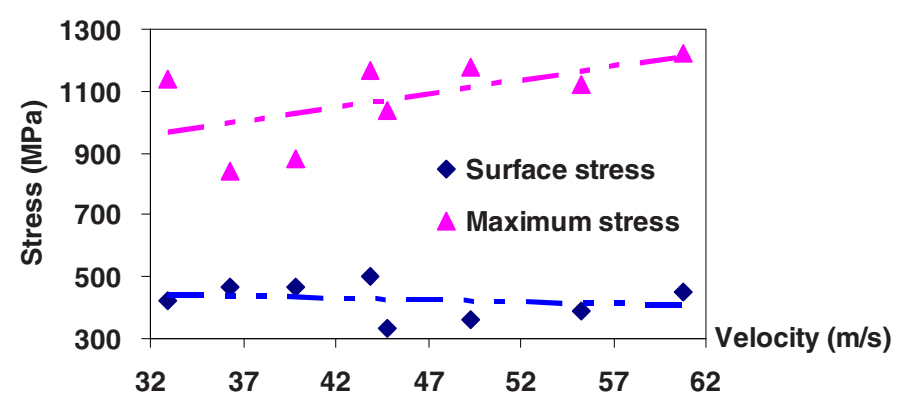

Fig. 3. Stress evolution vs shot velocity. 


\subsubsection{Effect of shot peening parameters on surface stresses}

The effects and interactions calculated from Table 4 are presented in Table 5 and illustrated in Figure 4 and Figure 5.

\begin{tabular}{|c|c|c|c|c|}
\hline Factor & $\begin{array}{lcl}\text { Effect on } & \text { surface } \\
\text { stress }(\mathrm{MPa}) & \\
\end{array}$ & $\%$ & $\begin{array}{l}\text { Effect on maximum } \\
\text { stress }(\mathrm{MPa})\end{array}$ & $\%$ \\
\hline$\varnothing\left(\right.$ and $\left.\Theta * \mathrm{t}^{*} \mathrm{P}\right)$ & -55 & 13 & -50 & 5 \\
\hline$\Theta($ and $\varnothing * \mathrm{t} * \mathrm{P})$ & 45 & 11 & 57 & 5 \\
\hline $\mathrm{t}($ and $\varnothing * \Theta * \mathrm{P})$ & -11 & 3 & 153 & 14 \\
\hline $\mathrm{P}($ and $\varnothing * \Theta * \mathrm{t})$ & -80 & 19 & 134 & 12 \\
\hline$\varnothing * \Theta$ and $\mathrm{t} * \mathrm{P}$ & -6 & 1 & -137 & 13 \\
\hline$\varnothing * \mathrm{t}$ and $\Theta * \mathrm{P}$ & 3 & 1 & 64 & 6 \\
\hline$\varnothing * \mathrm{P}$ and $\Theta * \mathrm{t}$ & -17 & 4 & -13 & 1 \\
\hline
\end{tabular}

Table 5. Effects of factors and of second order interactions. The percentage is relative to the average values, $425 \mathrm{MPa}$ and $1073 \mathrm{MPa}$ for surface and maximum stress respectively

For surface stress, it can be seen that second order interactions are significantly smaller than the effect of individual parameters. It was found that for the main parameters, the pressure has the most influence on surface residual stress, stress level decreases with increase of pressure. This can be explained by the fact that the carbonitrided layer has an important stress level and a particular material structure, when the pressure increase, it produce a change in the material structure, the effect of shot peening process give a less influence to the stress level. After the pressure, the shot size and angle of impact have more influence. A smaller shot size produces higher stress levels, because when the shot size decrease, the impact surface reduce produce the increase of hertz pressure which can increase the plastic deformation attached to residual stress. On the other hand, the affected depth is smaller. A bigger impact angle gives a bigger perpendicular velocity which, in turn, leads to higher stress levels. The exposure time have the least contribution between these 4 factors which means that the material is not far from saturation on the surface.

Several studies are consistent with this analysis: Lassithiotakis et al [8] show that the angle of impact is the parameter which has the strongest influence on surface stress with a distance between nozzle and specimen $80 \mathrm{~mm}$ maximum instead of $150 \mathrm{~mm}$ used in this work. Meguid et al [6] show that the magnitude of surface residual stress remains unchanged with different shot size in a single shot model, however, in practice, it is a shot beam that arrives to the material surface, thus the effect of shot will be more significant than with a single shot.

From the analysis of effect of parameters in Fig. 4, the maximum value of surface stress can be obtained by setting a combination like shot size and pressure at lower levels and the angle of impact and higher level. This conclusion according to the results in Table 4, the maximum surface stress is $502 \mathrm{MPa}$ which is achieved by using the above combination.

\subsubsection{Effect on maximum residual stress in depth}

For the main factors individually on maximum residual stress, the exposure time and pressure have the most influence indicated in Table 5 and Figure 5. Setting the exposure time and pressure with higher levels can be used to achieve a higher level of stress. For the interaction of parameter, the interaction between shot size and angle of impact and the interaction between exposure time and pressure have the most significant influence on the maximum residual stress. The choice of higher level for angle of impact and lower for shot size is better to improve the maximum stress in depth.

For the effect of pressure, it can be considered that the carbonitriding effect has much less influence in depth than in the surface. Therefore, with the relationship presented in the part of velocity effect, shot velocity increase proportional with the pressure, thus, more kinetic energy has been obtained by the shot peened material in the depth. 
The above results show that when the material is completely covered, an important difference of maximum stress is shown in Fig. 5 when the coverage arrives in $200 \%$.

By the theory and experimental method, Al-Obaid [1] has analyzed the shot peening process and show that the residual stress distribution can be calculated on function of the depth of plastic zone, Xiao et al [9] modeled the process taking into account the effect of shot radius, pressure and exposure time. It is presented that the maximum stress increase with the increase of pressure and exposure time. It is the same conclusion than the results of this work. Lassithiotakis et al [8] prove, by realizing tests, that the exposure time and pressure have the most influence on maximum residual stress. By the simulation method, model has done for a single impact. Meguid et al [6] show that the maximum stress remains the same with the difference of shot size. Schiffner [10] show that a better maximum stress can be obtained by a smaller shot. During the real shot peening process, a huge number of shot impact the surface bring a big difference than the condition of one shot.

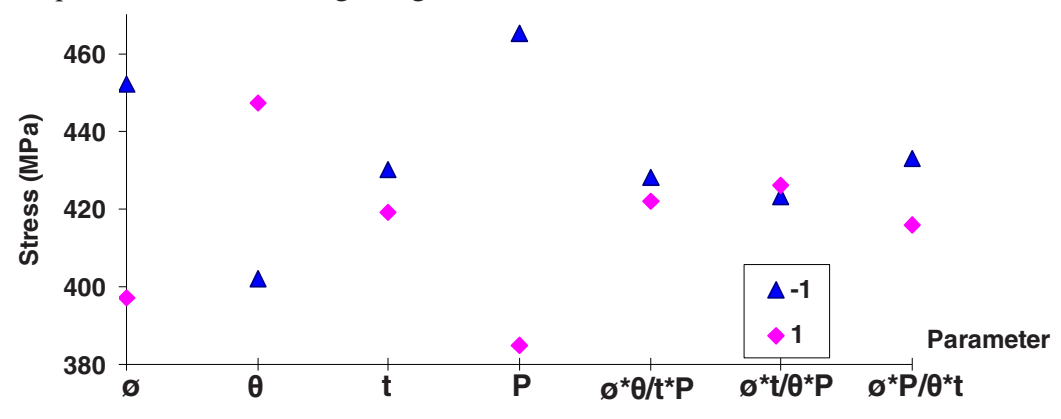

Fig. 4. Graphical presentation for the parameters effect on surface stress.

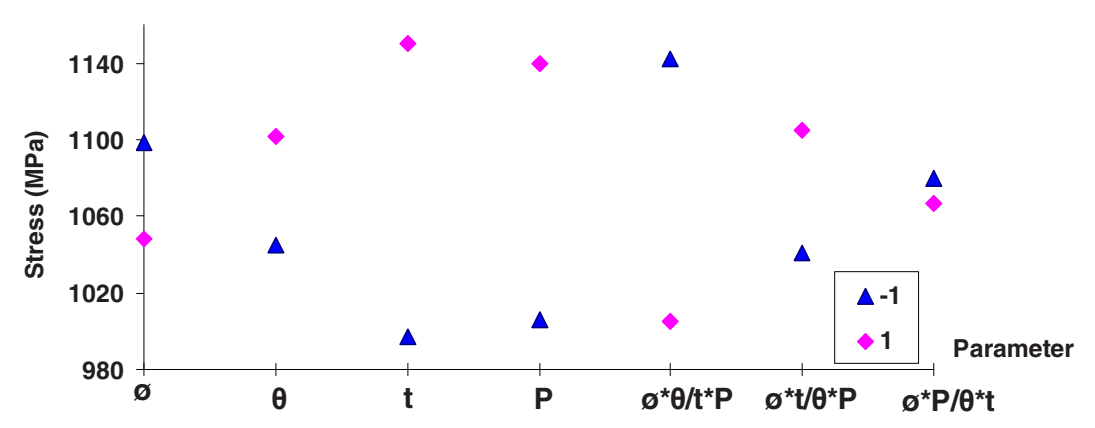

Fig. 5. Graphical presentation for the parameters effect on maximum stress

Consequently, in this study, to obtain a better maximum residual stress in depth, a combination of a higher levels for exposure time, pressure and angle of impact can be set up. Referring to the configuration in the Table 4 , configuration 8 can be considered as the reference.

\subsubsection{Distribution of residual stress}

In order to quantify the stress level after shot peening, two equations are proposed for surface stress and maximum stress. They are identified by a least square procedure from the obtained data and presented by equation 1 and 2. Where stresses are in MPa, diameter in $\mathrm{mm}$, time in second, angle in degree and pressure in bar.

$$
\begin{array}{r}
\sigma_{\text {Surf }}=137(\varnothing)-2.26(\theta)+3.75(t)+40.1(P)-500 \\
\sigma_{\text {Max }}=36.8(\varnothing)-3.45(\theta)-227(t)-265(P)+412+1.17(\varnothing \theta)+44.0(t P)
\end{array}
$$




\subsection{Results of hardness}

In the material shot peened, hardness is an important property to take into account because of its influence in the comportment mechanical. Several investigations dealing with this issue has been presented, $[2,3,11,12]$. During the measure of hardness by using the hardness test machine, a plastic zone who have a depth more important that the indentation depth has been studied by Gao [12]. The formula to determinate this plastic zone after indentation is as:

$$
\left(R_{c} / a\right) 3=E \cot (\alpha) / 3 \sigma_{Y} .
$$

$R_{c}$ is the radius of the plastic zone in $\mu \mathrm{m}$, a is the radius of indentation in $\mu \mathrm{m}, \alpha$ is the middle angle in the indenter head in degree. $\sigma_{\mathrm{m}}$ is the average stress in the plastic zone and $\sigma_{\mathrm{Y}}$ is the yield stress.

\begin{tabular}{cccccc}
\hline $\begin{array}{c}\text { Configur } \\
\text { ation }\end{array}$ & $\begin{array}{l}\mathrm{Rc} \\
(\mu \mathrm{m})\end{array}$ & $\sigma_{\mathrm{m}}(\mathrm{MPa})$ & $\begin{array}{l}\text { Hardness } \\
\text { measured }(\mathrm{MPa})\end{array}$ & $\begin{array}{l}\text { Hardness corrected } \\
\text { method Lee }(\mathrm{MPa})\end{array}$ & $\begin{array}{l}\text { Hardness } \\
\text { MethodCarlsson }(\mathrm{MPa})\end{array}$ \\
\hline 1 & 443 & -674 & 2303 & 1853 & 1928 \\
2 & 443 & -754 & 2306 & 1803 & 1887 \\
3 & 456 & -838 & 2178 & 1619 & 1712 \\
4 & 458 & -834 & 2158 & 1602 & 1695 \\
5 & 438 & -687 & 2358 & 1900 & 1891 \\
6 & 441 & -779 & 2324 & 1805 & 1991 \\
7 & 438 & -655 & 2355 & 1919 & 2060 \\
8 & 429 & -706 & 2452 & 1982 & \\
\hline
\end{tabular}

Table 7. Hardness en function of residual stress in shot peened material

The carbonitrided material has a measured hardness of $2146 \mathrm{MPa}$. By analyzing the results shown in Table 7 and Figure 6, shot peening increase the hardness of the material to an average measured value of 2300 by about $150 \mathrm{MPa}$. Angle, pressure and exposure time do not have significant effect but shot diameter does. Bigger diameter gives a harder material. As the residual stresses were measured independently, hardness values can be corrected. Based on finite elements and experimental results, Lee et al [2] and Carlsson et al [11] have proposed formulas (4) and (5) to take into account effect of residual stress

$$
\begin{array}{r}
H=H_{0}-2 \sigma_{R} / 3 \\
H=H_{0}\left(1+\sigma_{R} / 3 \sigma_{Y}\right)
\end{array}
$$

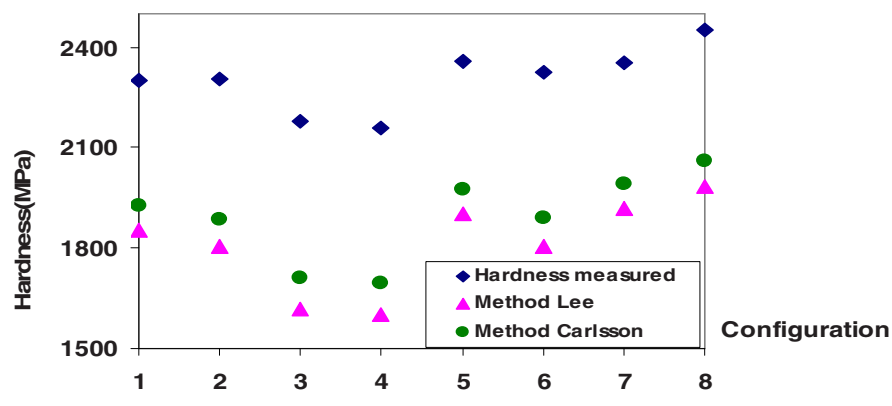

Fig. 6. Hardness determined by different methods

In these equations, the $\mathrm{H}$ is the hardness to determinate (MPa); $\mathrm{H}_{0}$ is the average hardness calculated on function of $\sigma_{\mathrm{m}}$ and measured hardness; $\sigma_{\mathrm{R}}$ is the residual stress which we take the $\sigma_{\mathrm{m}}$ to have a better precision and $\sigma_{Y}$ is the yield stress of material. The results determined by different methods are shown in Table 7. After correction, it ca be found that hardness levels are about 
$1893 \mathrm{Mpa}$ which are smaller than the initial hardness. This means that there are two phenomenons competitive after shot peening: a hardening of $400-500 \mathrm{MPa}$ due to compressive residual stress and a softening of 300-400MPa due to dislocation of relaxation martensite.

\section{Conclusions}

In this work, a study of residual stress and hardness on shot peened and carbonitrided material is presented by realizing a Taguchi method.

After a deep analysis on the experimental resultants, influence of the main process parameters has been quantified. It is shown that for surface stress, a smaller shot size and a bigger impact angle could produce higher stress levels, in another hand, surface stress level decreases with increase of pressure. For maximum stress in depth, exposure time and pressure have both the positive effect. A combination of a higher impact angle and a smaller shot size can also improve the maximum stress. The predictive equations to determinate the residual stress on function of these parameters are suggested.

Analysis of hardness has been presented following by taking into account the effect of plastic zone after indentation. The results indicated that for a shot peened carbonitrided material, the hardness level do not only depend on the residual stress, but also depend on the microstructure state due to carbonitriding treatment.

The results in this work can be useful to set up the process values of shot peening in industrial to enhance the residual stress of components to improve their mechanical performance.

Acknowledgement: The authors are grateful to ANRT (French Agency for Research and Technology) for the CIFRE grant supporting this work.

\section{References}

1. Y.F.Al-Obaid, Shot peening mechanics: experimental and theoretical analysis, Mechanics of Materials 19 251-260 (1995)

2. Y-H. Lee, D. Kwon, Measurement of residual stress effect by nanoindentation on elastically strained (100) W, Scripta Materialia 49 459-465 (2003)

3. J.L. Bucaille, S. Stauss, E. Felder, J. Michler, Determination of plastic properties of metals by instrumented indentation using different sharp indenters, Acta Materialia, 51 1663-1678 (2003)

4. Z.M. Xiao, W.C. Fok, D. T. Lwin, Parametric study of residual stress due to shot peening, Journal of materials processing Technology, 19469 - 483 (1993)

5. P.M. George, Nisha Pillai, Nisha Shah, Optimization of shot peening parameters using Taguchi technique, Journal of Materials Processing Technology 153-154, 925-930 (2004)

6. S.A.Meguid, G. Shagal, J.C.Stranart, J. Daly, Three-dimensional dynamic finite element analysis of shot peening induced residual stresses, Finite Elements in Analysis and Design, 31 179191 (1999)

7. T. Hong, J.Y.Ooi, B. Shaw, A numerical simulation to relate the shot peening parameters to the induced residual stresses, Engineering Failure Analysis (2008)

8. D. Lassithiotakis, C. J. Aylott, B. A. Shaw, J.Ooi and F. Petit Renaud, Optimising shot peening parameters using DoE, ICSP9 : shot Peening, (2005)

9. Z.M.Xiao, W.C. Fok and D.T.Lwin, Effects of air-blast pressure and exposure time on the shot-peening process, Journal of materials Processing Technology, 39 13-20 (1993)

10. K. Schiffner, C. Droste Gen. Helling, Simulation of residual stresses by shot peening, Computers and Stuctures, 72 329-340 (1999)

11. S.Carlsson, P.L.Larsson, On the determination of residual stress and strain fields by sharp indentation testing. Part I: Theoretical and numerical analysis, Acta mater. 49 2179-2191 (2001)

12. X. L. Gao, X.N.Jing, G.Subhash, Two new expanding cavity models for indentation deformation of elastic strain hardening material, International Journal of Solids and Structures $\mathbf{4 3}$ 2193-2208 (2006) 